\title{
FRANÇOIS RAGUENET, JEAN-LAURENT LE CERF DE LA VIÉVILLE, La Première Querelle de la musique italienne (1702-1706)
}

\section{Giovanna Bencivenga}

\section{OpenEdition}

\section{Journals}

\section{Edizione digitale}

URL: https://journals.openedition.org/studifrancesi/43873

DOI: 10.4000/studifrancesi.43873

ISSN: 2421-5856

\section{Editore}

Rosenberg \& Sellier

\section{Edizione cartacea}

Data di pubblicazione: 1 juin 2021

Paginazione: 216

ISSN: 0039-2944

\section{Notizia bibliografica digitale}

Giovanna Bencivenga, «franç̧oIs Raguenet, JeAn-LauRent le cerf de LA VIÉville, La Première Querelle de la musique italienne (1702-1706)», Studi Francesi [Online], 193 (LXV | I) | 2021, online dal 01 juillet 2021, consultato il 14 octobre 2022. URL: http://journals.openedition.org/studifrancesi/43873 ; DOI: https:// doi.org/10.4000/studifrancesi.43873

Questo documento è stato generato automaticamente il 14 octobre 2022

\section{(c) $($ ) $(9)$}

Creative Commons - Attribuzione - Non commerciale - Non opere derivate 4.0 Internazionale - CC BYNC-ND 4.0

https://creativecommons.org/licenses/by-nc-nd/4.0/ 


\title{
FRANÇOIS RAGUENET, JEAN-LAURENT LE CERF DE LA VIÉVILLE, La Première Querelle de la musique italienne (1702-1706)
}

\author{
Giovanna Bencivenga
}

\section{NOTIZIA}

FRANÇOIS RAGUENET, JEAN-LAURENT LE CERF DE LA VIÉVILLE, La Première Querelle de la musique italienne (1702-1706), éd. L. Naudeix, Paris, Classiques Garniers, «Bibliothèque du XVII ${ }^{\mathrm{e}}$ siècle» $30,2018,930 \mathrm{p}$.

1 L'operazione di Laura Naudeix è lodevole. La studiosa ha infatti realizzato un progetto ambizioso, il cui valore è innegabile per gli specialisti del Seicento francese (e, in modo particolare, per gli studi relativi al periodo che intercorre tra la fine del Grand Siècle e i primi anni del secolo dell'Éncyclopédie): sono raccolti in un solo volume i testi della polemica conosciuta col nome di Première Querelle de la musique italienne, dovuta alla pubblicazione nel 1702 del Parallèle des Italiens et les Français en ce qui regarde la musique et les opéras ad opera dell'abbé François Raguenet, il quale ebbe modo di visitare la penisola (durante un soggiorno al seguito del cardinale Bouillon) e di apprezzarne la varietà in campo musicale. Il valore documentario dell'opera di Raguenet risiede soprattutto nella sua capacità di superare le descrizioni più comuni aventi come punto di riferimento principalmente la sontuosa e decadente Venezia: il religioso ha l'opportunità di visitare città come Roma, Bologna, Torino e di restituire, dunque, un ritratto più eterogeneo della creazione estetica e musicale peninsulare. Ma un altro motivo di interesse è dato anche dal fatto che l'opera di Raguenet s'iscrive in un contesto di particolare entusiasmo in Francia per la musica italiana. Tuttavia, mentre questo interesse si concretizza in zone marginali del campo editoriale e sociale, lo 
scritto del canonico francese pone la questione della musica italiana in primo piano: Raguenet sostiene, in effetti, che uno dei pregi maggiori della musica transalpina è dovuto principalmente alla compresenza di una lingua, l'italiano, che ne sostenga le belle qualità espressive. Ed è proprio l'entrata in scena dell'elemento linguistico che spinge il rouennese Jean-Laurent Le Cerf de La Vieville ad un'energica risposta nella sua Comparaison de la musique italienne et de la musique française, où, en examinant en détail les avantages des spectacles et le mérite des deux nations, on montre quelles sont les vraies beautés de la musique pubblicata nel 1704. La presenza del binomio lingua/musica, còlto nella sua problematicità e nella sua diversità di resa tra le due nazioni, si ricollega alla polemica linguistico- letteraria conosciuta come "Polemica Orsi-Bouhours" e avviata dalla pubblicazione della Manière de bien penser dans les ouvrages de l'esprit (1687) in cui il gesuita Dominique Bouhours deplorava alcuni eccessi stilistici e retorici della lingua italiana, elogiando, invece, l'eccellenza della lingua francese, giunta grazie all'epoca d'oro luigiana al suo «point de perfection».

Dopo una nutrita introduzione, Laura Naudeix mette ordine tra i principali testi della polemica, non tralasciando di annettere le critiche dei Mémoires de Trévoux (che pure giocarono un ruolo fondamentale nella Polemica Orsi-Bouhours) e del Journal des savants, a testimonianza dell'ampia diffusione della querelle. L'opera è inoltre corredata di un utile glossario per i termini più tecnici e della riproduzione dei frontespizi di copertina, che restituiscono - in chiave di storia del libro - un'idea più precisa delle caratteristiche della polemica. Il lavoro di Laura Naudeix sistematizza una massa critica di testi notevole cosicché esso possa essere di supporto nello studio di quel periodo di transizione fondamentale che fu la Querelle des Anciens et des Modernes, a cui i testi di Raguenet e Le Cerf sembrano essere particolarmente sensibili. 